\title{
Enhancement of Glutamate Release by L-Fucose Changes Effects of Glutamate Receptor Antagonists on Long-Term Potentiation in the Rat Hippocampus
}

\author{
Henry Matthies, ${ }^{1,4}$ Helmut Schroeder, ${ }^{1}$ Karl-Heinz Smalla, ${ }^{2,3}$ and Manfred Krug ${ }^{1}$ \\ ${ }^{1}$ Institute of Pharmacology and Toxicology, Faculty of Medicine, University Otto von Guericke, 39120 Magdeburg, Germany; ${ }^{2}$ Leibnitz-Institute \\ for Neurobiology, 39008 Magdeburg, Germany
}

\begin{abstract}
In previous studies L-fucose has been shown to facilitate long-term memory formation and to enhance and prolong long-term potentiation (LTP). To search for possible presynaptic or postsynaptic mechanisms that are affected by L-fucose, we examined the effect of L-fucose on (1) inhibition of LTP induction via glutamate receptors by antagonists, (2) paired-pulse facilitation, and (3) presynaptic transmitter release. Coapplication of $0.2 \mathrm{~mm}$ L-fucose with the competitive $N$-methyl-D-aspartate (NMDA) receptor antagonist, D-2-amino-5-phosphonovalerate (AP5), or coapplication of $0.2 \mathrm{~mm}$ L-fucose in the presence of an inhibitor for class I/II metabotropic glutamate receptors, (S)- $\alpha$-methyl-4-carboxyphenylglycine (MCPG), reversed LTP blockade in the CA1-region of hippocampal slices. In contrast, L-fucose had no effect on the LTP blockade by the noncompetitive NMDA ion-channel blocker (5R,10S)-(+)-5-Methyl-10,11-dihydro-5H-dibenzo[a,d]cyclohepten-5, 10-imine hydrogen maleate (MK-801). Paired-pulse facilitation, which is a primarily presynaptic phenomenon of short-term plasticity, was decreased in the presence of $0.2 \mathrm{~mm}$-fucose. Furthermore, L-fucose enhanced the $\mathrm{K}^{+}$-stimulated release of $\left[{ }^{3} \mathrm{H}\right]$-D-aspartate from preloaded hippocampal slices in a concentration-dependent manner. These observations demonstrate an influence of $\mathrm{L}$-fucose on transmitter release that in turn can increase transmitter availability at postsynaptic glutamate receptors. This effect of L-fucose may contribute to the LTP facilitation seen in vitro and in vivo as well as to improvement in memory formation.
\end{abstract}

Investigations of protein glycosylation suggest a pivotal role for glycoproteins and their glycan structures in learning and memory (for reviews see Matthies 1988; Breen et al. 1998). Enhanced glycoprotein processing after learning experiments results in an increased incorporation of the terminal saccharides L-fucose and sialic acid into the carbohydrate chains of brain glycoconjugates (Jork et al. 1986; Regan and Fox 1995; Rose 1995). Application of glycan chain synthesis inhibitors has been shown to prevent long-term memory formation (Jork et al. 1986, 1989; Crowe et al. 1994; Alexinsky et al. 1997). Furthermore, L-fucose improves memory consolidation in a discrimination learning task (Wetzel et al. 1980).

Hippocampal long-term potentiation (LTP) is widely accepted as a model to describe elementary cellular mechanisms involved in long-lasting information storage in the brain (e.g., Bliss and Collingridge 1993). Glycoprotein pro-

\footnotetext{
${ }^{3}$ Present address: Institute of Medical Neurobiology, Faculty of Medicine, University Otto von Guericke, Leipziger Strasse 44, 39120 Magdeburg, Germany.

${ }^{4}$ Corresponding author.

E-MAIL henry.matthies@medizin.uni-magdeburg.de; FAX (0391)6715869.
}

cessing also plays a crucial role in the maintenance of LTP. An increase in $\left[{ }^{3} \mathrm{H}\right]$-fucose incorporation into glycoproteins and enhanced fucosyltransferase activity have been reported after LTP induction in the CA1 region (Angenstein et al. 1992). Inhibitors of glycoprotein processing, in particular 2-deoxy-D-galactose as a specific inhibitor of glycoprotein fucosylation, prevent LTP maintenance (Krug et al. 1991; Matthies et al. 1999). Moreover, the presence of $\mathrm{L}$ fucose or the trisaccharide 2 '-fucosyllactose during tetanic stimulation drastically increases LTP both in vivo and in vitro (Krug et al. 1994; Matthies et al. 1996). So far, the effects of L-fucose on memory formation and LTP maintenance have been discussed mainly in terms of increased fucose incorporation into glycan chains of newly synthesized glycoproteins (Wetzel et al. 1980; Matthies 1988; Krug et al. 1994; Matthies et al. 1999). However, the rapid enhancement of LTP in the presence of L-fucose immediately after tetanization (Krug et al. 1994; Matthies et al. 1996) would require rather fast synaptic mechanisms. Therefore, we tested L-fucose for direct post- and/or presynaptic effects which might explain the fast enhancement of LTP.

L-fucose might interact with these receptors around the ligand binding site or the ion channel pore and thus modu-

LEARNING \& MEMORY 7:227-234 @ 2000 by Cold Spring Harbor Laboratory Press ISSN1072-0502/00 \$5.00

$$
\begin{aligned}
& \begin{array}{llllllllllllllllllllllll} 
& E & A & R & N & I & N & G & \mathbf{Z} & M & E & M & O & R & Y
\end{array} \\
& \text { www.learnmem.org }
\end{aligned}
$$


late LTP induction and maintenance. Alternatively, increased glutamate availability due to enhanced presynaptic glutamate release from the presynaptic site mediated by L-fucose can contribute to LTP enhancement.

The paired-pulse stimulation paradigm and the measurement of $\mathrm{K}^{+}$-stimulated $\left[{ }^{3} \mathrm{H}\right]$-D-aspartate release are approaches for analyzing changes in presynaptic transmitter release. Paired-pulse facilitation (PPF) is characterized as an alteration in transmitter release probability caused by a conditioning stimulus that leads to an enhanced response to a second test stimulus spaced from the conditioning stimulus by about 50 msec (e.g., Zucker 1989). PPF is assumed to be a primarily presynaptic event (Zucker 1989; Schulz et al. 1994; Commins et al. 1998), in which a change in the ratio of the second answer to the first one would reflect a change in transmitter release probability. The fast facilitation of LTP in the presence of L-fucose might be explained if an increase of transmitter release by L-fucose could be substantiated. LTP induction may include an early step of enhanced transmitter release (Bliss et al. 1986; Canevari et al. 1994). An increase of transmitter available at the postsynaptic receptor thus may contribute to LTP expression or interfere with glutamate receptor antagonists in modulating LTP induction.

To determine if $\mathrm{L}$-fucose can modulate the presynaptic and/or postsynaptic mechanisms, we studied the effect of L-fucose on LTP induction after inhibition of different glutamate receptors by antagonists, paired-pulse facilitation, and presynaptic transmitter release.

\section{RESULTS}

\section{L-Fucose Application and \\ NMDA-Receptor Inhibition}

LTP in the hippocampal CA1 region can be blocked by competitive (e.g., D-2-amino-5-phosphonovalerate [AP5]) and noncompetitive ((5R,10S)-(+)-5-Methyl-10,11-dihydro5H-dibenzo[a,d]cyclohepten-5,10-imine hydrogen maleate [MK-801]) NMDA receptor antagonists that bind to the NMDA receptor-coupled ion channel and can be modulated by antagonists of the metabotropic glutamate receptors (e.g., (S)- $\alpha$-methyl-4-carboxyphenylglycine [MCPG]). In the experiments described here we applied L-fucose with these inhibitors before and during LTP induction to investigate effects of L-fucose on glutamate receptors.

A long-lasting and stable LTP of the fEPSP was induced by high-frequency stimulation in control experiments without drug treatment (Fig. 1). Tetanic stimulation in the presence of the competitive NMDA receptor antagonist AP5 (50 $\mu \mathrm{M})$ induced only short-term potentiation. The slope function of the fEPSP returned to control level immediately after tetanization. However, when we coapplied $50 \mu \mathrm{M}$ AP5 with $0.2 \mathrm{~mm}$ L-fucose, the blocking effect of AP5 was partially reversed. As described earlier (Matthies et al. 1996), $30 \mathrm{~min}$

\section{A}

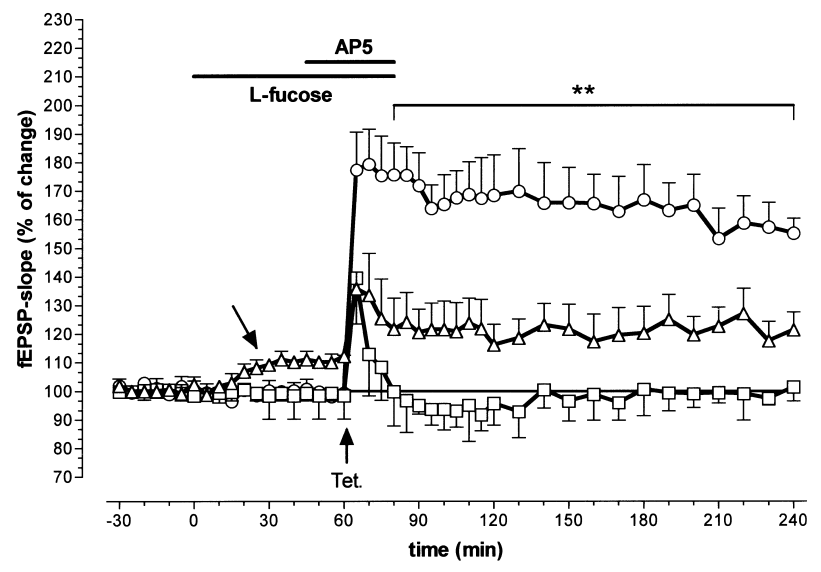

B

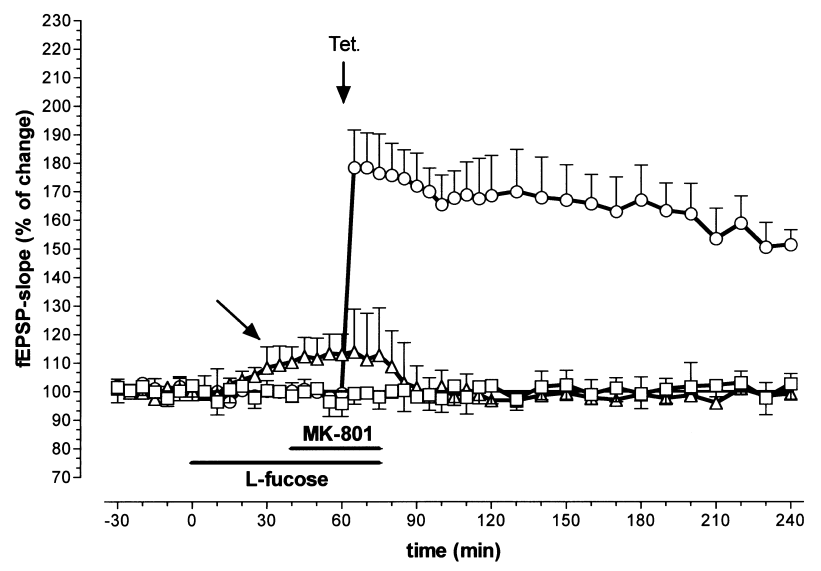

Figure 1 Influence of coapplication of $0.2 \mathrm{~mm}$ L-fucose with 50 $\mu \mathrm{M}$ of the competitive NMDA receptor antagonist AP5 (A) and 15 $\mu \mathrm{M}$ of the noncompetitive antagonist MK-801 $(B)$ on LTP in the hippocampal CA1 region. ( $\square$ ) LTP of the fEPSP in the presence of the antagonist; $(\triangle)$ LTP of the fEPSP when L-fucose and the antagonist are coapplied; (O) LTP control. (Horizontal bars) Application periods, (vertical bars) S.E.M.; $(* *) P<0.02$. (Number of animals $(N)$ in $A$ : coapplication $=8, \mathrm{AP} 5=7 ; N$ in $B$ : coapplication $=8$, MK$801=7$ ). Unlabeled arrows indicate the slow increase of the fEPSP during L-fucose application. Arrows labeled "Tet." indicate the time point of tetanization.

after L-fucose application an increase of the slope function of the nontetanized fEPSP was observed (arrows in Figs. 1 and 2). Furthermore, AP5 did not suppress the tetanus-induced LTP. A considerable long-lasting and stable potentiation was found until $4 \mathrm{hr}$ after tetanization (Fig. 1A). However, the degree of potentiation in control experiments was not reached. A significant deviation between the group of AP5-treated and the group of AP5/L-fucose treated slices was seen for the fEPSP-slope ( $\geq 15 \mathrm{~min} ; P<0.02 ; N=8$ ).

Application of the noncompetitive NMDA-receptor ion channel blocker MK-801 (15 $\mu \mathrm{M})$ also totally blocked LTP in

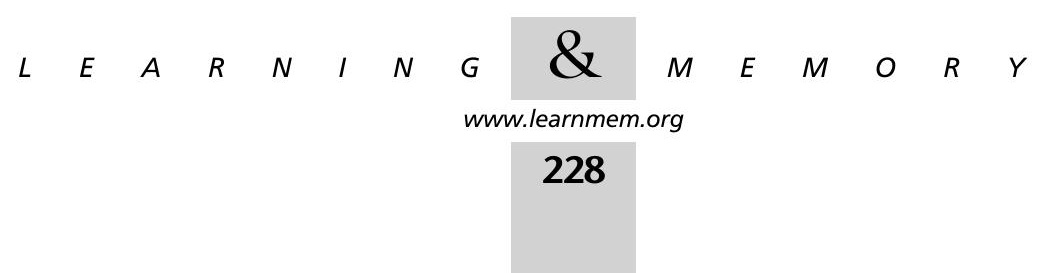




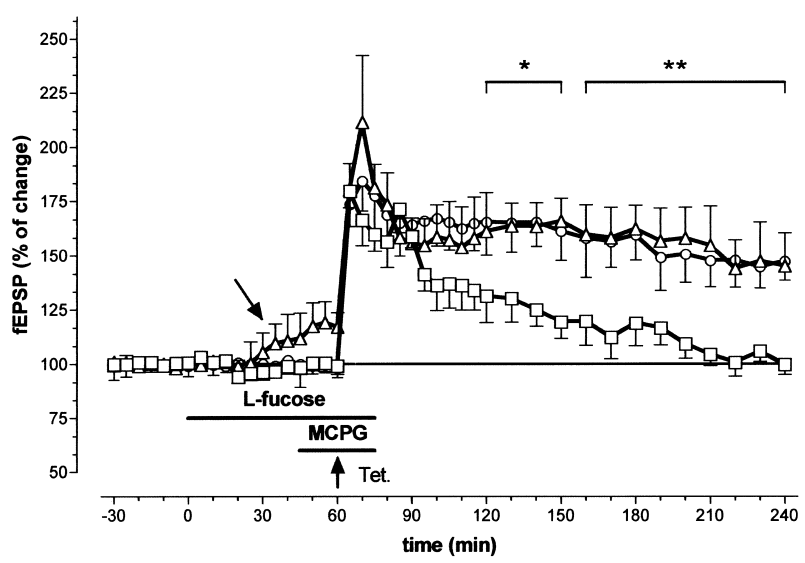

Figure 2 Influence of the coapplication of $0.2 \mathrm{~mm}$ L-fucose with $500 \mu \mathrm{M}$ of the antagonist for metabotropic glutamate receptors, MCPG, on LTP in the hippocampal CA1 region. ( $\square$ ) Potentiation of the fEPSP in the presence of MCPG; $(\triangle)$ potentiation of the fEPSP when L-fucose and MCPG are coapplied; $(\bigcirc)$ potentiation of the fEPSP without any drug application. (Horizontal bars) Application periods for L-fucose (upper bar) and MCPG (lower bar); (vertical bars) S.E.M.; $\left.{ }^{*}\right) P<0.05$; (**) $P<0.02$. ( $N$ for $M C P G=7, N$ for coapplication $=7$ ). Unlabeled arrow indicates the slow increase of the fEPSP during L-fucose application. Arrow labeled "Tet." indicates the time point of the high-frequency stimulation.

the CA1 region (Fig. 1B). However, in contrast to the group treated with AP5, the coapplication of $0.2 \mathrm{~mm}$ L-fucose did not reverse or weaken the antagonistic effect of MK 801 in this group of slices. Both MK-801 treatment (Fig. 1B, boxes; $N=7$ ) and coapplication of MK-801 with L-fucose (Fig. 1B, triangles; $N=8$ ), showed the same time course of LTP inhibition.

\section{L-Fucose Application and mGluR Inhibition}

Because of the studies that addressed the important role of mGluRs in mechanisms of LTP, we also coapplied a specific antagonist of these receptors together with L-fucose and induced LTP. The application of $500 \mu \mathrm{M} \mathrm{MCPG,} \mathrm{a} \mathrm{mGluR}$ antagonist with a broad-spectrum effect on class I/II mGluRs (Watkins and Collingridge 1994), blocked the late phase of LTP in the CA1 region (Fig. 2). The slices were incubated with $500 \mu \mathrm{M} \mathrm{MCPG}$ for $25 \mathrm{~min}$. The standard tetanization procedure was applied 15 min after starting the application. In the presence of MCPG, $5 \mathrm{~min}$ after tetanization the fEPSP slope was $180.26 \% \pm 12.25 \%$ of the control ( $N=6$; Fig. 2) and did not deviate from that obtained during L-fucose application (see below). However, soon after tetanization the potentiation of the fEPSP slope declined, and a return to the baseline value was observed after $200 \mathrm{~min}$. On the other hand, the preincubation with L-fucose and additional application of MCPG did not show any changes in LTP time course compared with untreated control slices. Significant differences in the time course of LTP between MCPG treated slices and MCPG/L-fucose-treated slices occurred $\geq 120$ min after tetanization $(P<0.05)$.

\section{L-Fucose Application and Paired-Pulse Facilitation}

We used two different paradigms of paired-pulse facilitation to investigate the influence of L-fucose on presynaptic transmitter release. An enhancement of the second answer occurs when glutamatergic synaptic potentials are evoked at interstimulus intervals (ISIs) $<100 \mathrm{msec}$, which is indicative of enhanced transmitter release (Fig. 3B). Substances that increase transmitter release diminish the degree of PPF (Mennerick and Zorumski 1996). This effect was observed in both experimental paradigms. As Figure 3A, B shows, PPF
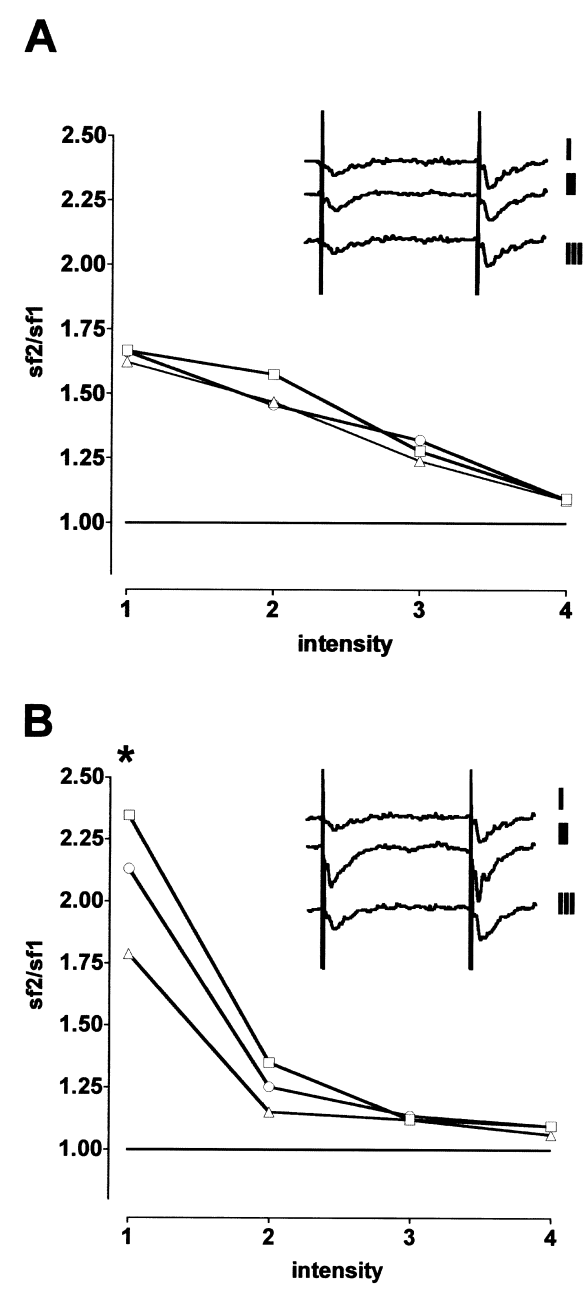

Figure 3 Influence of $0.2 \mathrm{~mm}$ L-fucose and D-fucose on pairedpulse facilitation (PPF) in the hippocampal CA1 region when using a fixed interstimulus interval of $50 \mathrm{msec}$ and increasing stimulus intensity. (Abscissa) Paired-pulse ratio of the fEPSP-slope (sf); (ordinate) stimulus intensity: $1=$ threshold intensity; 2, 3, and $4=$ threshold intensity times $1.5,2$, and 2.5 , respectively. (A) Control records with D-fucose application ( $N=6$ animals). (B) L-fucose application ( $N=8$ animals). $(*) P<0.05$. ( $\square$ ) Predrug period; $(\triangle)$ 60 min after beginning of the fucose application; $(\bigcirc)$ after washout; (vertical bars) S.E.M. Inserts in $(A)$ and $(B)$ show analogous examples of the fEPSP evoked by near-threshold intensity ( $I=$ before, $\mathrm{II}=$ during substance application, III = after washout).

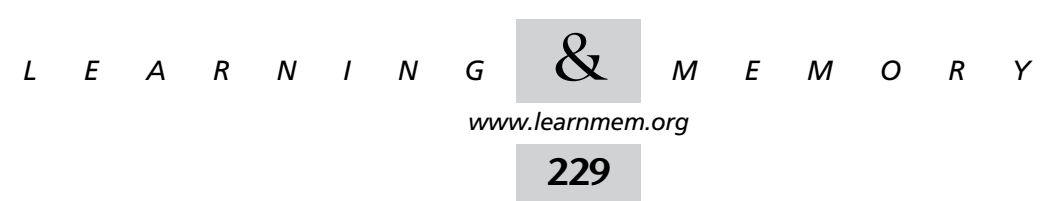


induced by double pulse stimulation with a fixed ISI of 50 msec depends on stimulus intensity. When the fEPSP was evoked by stimulation with near-threshold intensity, the ratio of the second response to the first (R2/R1) was $2.35 \pm 0.16$. Increasing the stimulus intensity decreased the paired-pulse ratio. With 2.5-fold threshold intensity, a value of $1.09 \pm 0.1$ was seen. Addition of $0.2 \mathrm{~mm}$-fucose to the perfusion medium decreased the ratio significantly to 1.76 at threshold intensity $(P<0.05, N=8)$. At higher intensities no effects were seen. As shown in Figure 3B, the PPF ratio returned to the value of the predrug period after washing out the substance. Figure $3 \mathrm{~A}$ indicates stability of the PPF ratio under control conditions ( $0.2 \mathrm{~mm}$ D-fucose). As Figure $4 \mathrm{~B}$ shows, PPF also was influenced by L-fucose application

\section{A}

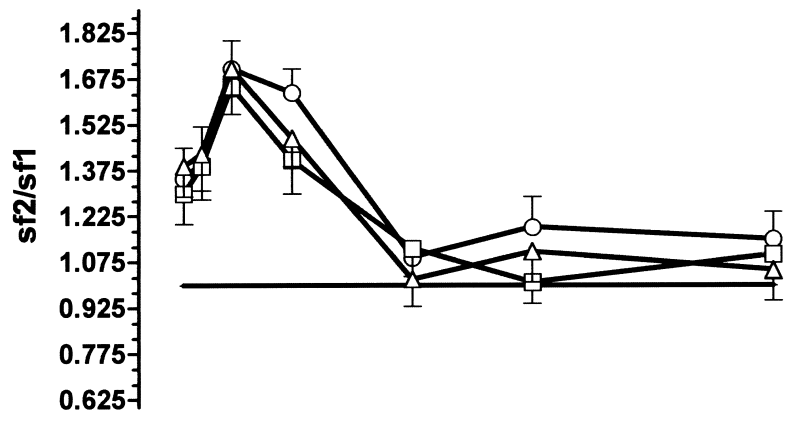

\begin{tabular}{llllllllllll}
\hline 0 & 50 & 100 & 150 & 200 & 250 & 300 & 350 & 400 & 450 & 500
\end{tabular} ISI (ms)

\section{B}

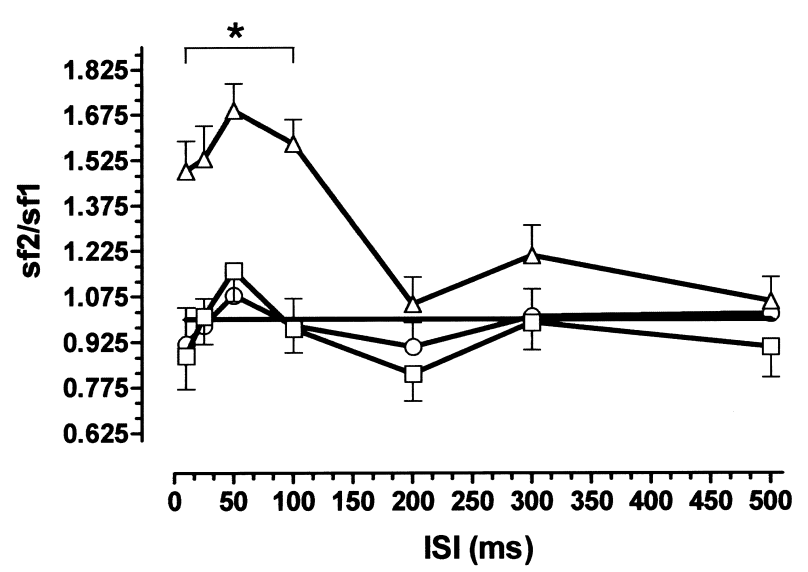

Figure 4 Influence of $0.2 \mathrm{~mm}$ L-fucose or D-fucose on paired-pulse facilitation (PPF) in the hippocampal CA1 region induced with near-threshold intensity and variation of interstimulus intervals (ISI). (A) Control with D-fucose application ( $N=7$ animals); (B) Lfucose application ( $N=8$ animals). ( $\triangle$ ) Predrug period; $(\square)$ during drug application; $(O)$ after wash out. Values in $(A)$ were recorded at the same times as in $(B) ;\left(^{*}\right) P<0.05$; (vertical bars) S.E.M.
A

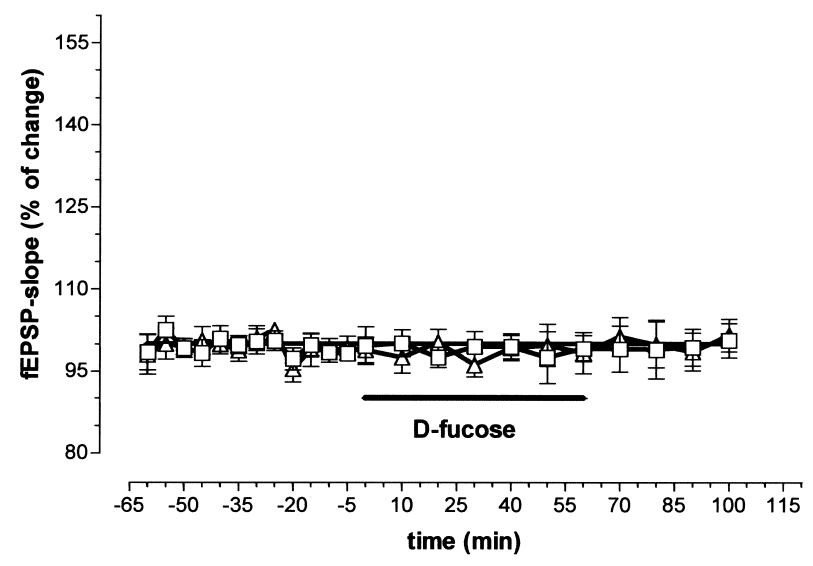

B

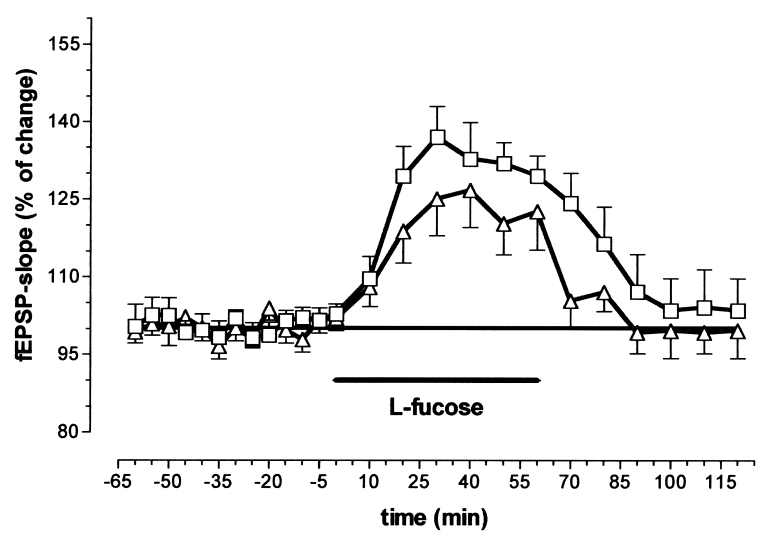

Figure 5 Influence of $0.2 \mathrm{~mm}$ D-fucose $(A)$ and $0.2 \mathrm{~mm}$ L-fucose $(B)$ on the slope function of the fEPSPs recorded in the CA1 region after paired-pulse stimulation with a fixed interstimulus interval of 50 msec and near-threshold intensity. ( $\square$ ) First EPSP; $(\triangle)$ second EPSP $(N=8$ animals). Ordinates indicate percent deviation from predug values. (Horizontal bars) Substance application; (vertical bars) S.E.M.

when the ISI was varied systematically and the intensity was fixed at a low level. In the predrug period PPF was detectable with ISIs of 10, 20, 50, and $100 \mathrm{msec}$. The ratio R2/R1 was obviously higher than 1.0. The application of $0.2 \mathrm{~mm}$ L-fucose decreased the PPF ratio, especially for ISIs of 10 , 20, 50, and $100 \mathrm{msec}$ (Fig. 4B). The inactive isomer D-fucose did not influence the PPF ratio (Fig. 4A). In Figure 5 the slope function of the first and second fEPSP were plotted separately for perfusion with D-fucose (Fig. 5A) and L-fucose (Fig. 5B). Although the application of D-fucose had no effect on the slope function of the fEPSP, fEPSP was enhanced by L-fucose. As can be seen in Figure 5B, the slope of the first response (boxes) increased to a greater extent than that of the second response (triangles). As a consequence, the PPF

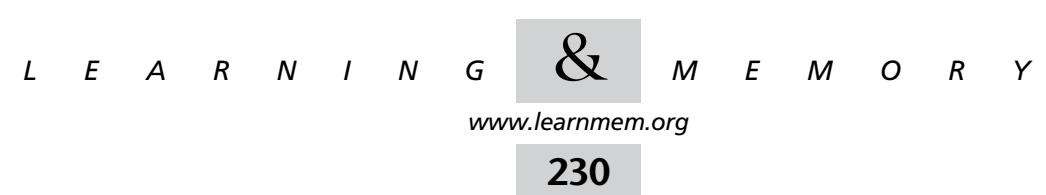


ratio must decline. These results indicate a facilitation of transmitter release by L-fucose.

\section{L-Fucose Application and Glutamate Release}

The influence of L-fucose on $\left[{ }^{3} \mathrm{H}\right]$-D-aspartate release from hippocampal slices was also investigated. Aspartate can substitute for the natural transmitter glutamate in brain tissue (Zablocka and Domanska-Janik 1994) and is released in the same way as glutamate. Because aspartate is not metabolized, radioactively labeled aspartate liberation reflects the release of the natural transmitter with better accuracy than labeled glutamate itself. In our experiments the basal (data not shown) and the $\mathrm{K}^{+}$-stimulated releases from hippocampal slices preloaded with $\left[{ }^{3} \mathrm{H}\right]$-D-aspartate were enhanced by L-fucose $(N=5)$ in a concentration-dependent manner.

L-fucose concentrations of $10 \mu \mathrm{m}$ and $100 \mu \mathrm{m}$ had a significant effect on the $\left[{ }^{3} \mathrm{H}\right]$-D-aspartate release (Fig. 6), whereas $1 \mu \mathrm{M}$ L-fucose did not alter the release (data not shown). The basal and $\mathrm{K}^{+}$-stimulated $\left[{ }^{3} \mathrm{H}\right]$-D-aspartate re-

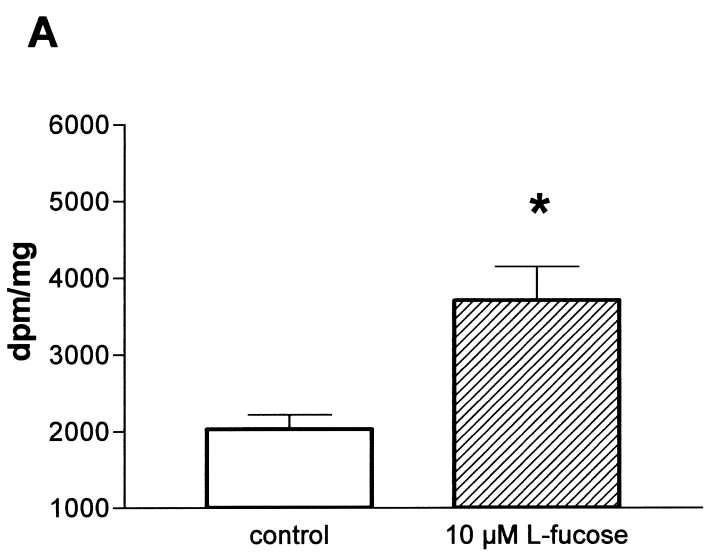

B

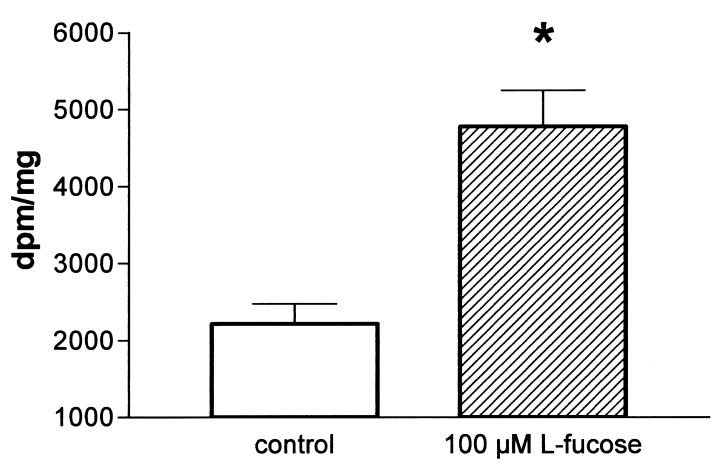

Figure 6 Influence of L-fucose on $\left[{ }^{3} \mathrm{H}\right]$-D-aspartate release from hippocampal slices in comparison to control slices. The $\mathrm{K}^{+}$-stimulated amino acid release from hippocampal slices ( $N=5$ animals) was enhanced by L-fucose in a concentration-dependent manner. (A) $10 \mu \mathrm{M}$ L-fucose; (B) $100 \mu \mathrm{M}$ L-fucose. (Vertical bars) S.E.M.; $\left(^{*}\right)$ $P<0.05$ lease from hippocampal slices was unchanged after addition of the physiological inactive isomer D-fucose (data not shown).

\section{DISCUSSION}

Hippocampal LTP is a complex phenomenon of neuronal plasticity realized by different pre- and postsynaptic processes. This synaptic enhancement, lasting hours or days, is discussed as a possible cellular mechanism involved in learning and memory formation (Bliss and Collingridge 1993; Frey and Morris 1997). Meanwhile it is generally accepted that, like memory consolidation, the late maintenance of LTP depends on undisturbed protein synthesis and glycoprotein processing during a critical time window. Inhibitors of protein synthesis or of glycoprotein processing disturb memory consolidation and prevent maintenance of LTP (Jork et al. 1986, 1989; Matthies 1988; Krug et al. 1991; Crowe et al. 1994; Rose 1995; Matthies et al. 1999). On the other hand, substances which improve memory consolidation by interfering with biomacromolecular synthesis, such as orotic acid and the monosaccharide L-fucose (Wetzel et al. 1980) also enhance or prolong LTP (Krug et al. 1989, 1994; Matthies et al. 1996). Enhanced $\left[{ }^{3} \mathrm{H}\right]$-fucose incorporation into hippocampal glycoproteins has been demonstrated after LTP induction (Angenstein et al. 1992). However, the fast increase of LTP magnitude immediately after tetanization in the presence of L-fucose points to additional direct and fast effects (Krug et al. 1994; Matthies et al. 1996). Candidates for direct interference are fucosylated receptor proteins, ion channels, or extracellular matrix proteins and their putative binding proteins (Varki 1993). The extracellular supply of fucose in sufficient concentrations could, for example, modulate transmitter release, receptor function, or cell-cell communication by competition with endogenous ligands. The concentrations used in our experiments are comparable to those used in learning experiments or LTP studies (Wetzel et al. 1980; Krug et al. 1994). However, they are not physiological because free $\mathrm{L}-\mathrm{fucose}$ is absent in the brain. Interestingly, despite its function as the major energy source in the brain, the monosaccharide glucose applied at concentrations comparable to that of L-fucose can increase acetylcholine release in the central nervous system during a learning experiment and enhance memory (Ragozzino et al. 1996), perhaps by increasing acetylcholine synthesis (Durkin et al. 1992). This may explain its memory-enhancing effect. Our results provide evidence that the monosaccharide $\mathrm{L}$-fucose also exerts its effect on LTP at least in part by presynaptic mechanisms.

An enhanced glutamate release could be deduced from our electrophysiological data. Paired-pulse facilitation, which is considered to be a primarily presynaptic phenomenon (Schulz et al. 1994; Commins et al. 1998), was influenced in a way that indicates enhanced transmitter release in the presence of L-fucose. We demonstrated this effect in

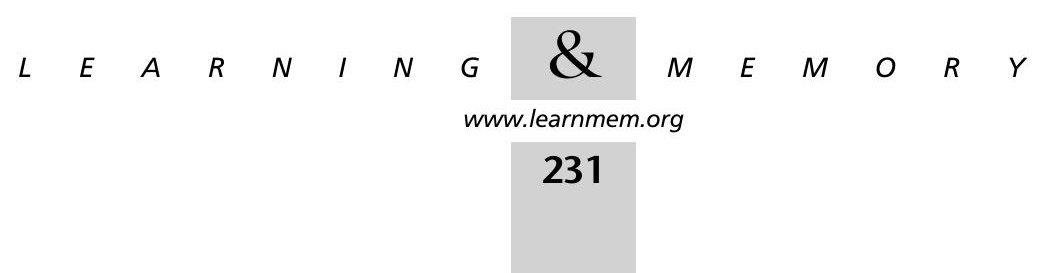


two experimental paradigms. When PPF was induced with a fixed ISI and a stepwise increase in stimulus strength, a considerable facilitation was seen only near threshold intensity. The ratio R2/R1 decreased with higher stimulus intensities. This confirms earlier results and can be explained by saturation phenomena at higher intensities or interactions with postsynaptic phenomena (e.g., Leung and $\mathrm{Fu}$ 1994). L-Fucose significantly decreased PPF when induced with near-threshold stimulus intensity, and this effect is interpreted as an increase in transmitter release (Mennerick and Zorumski 1996; Commins et al. 1998; Kato et al. 1999). Varying the ISI and holding the stimulus intensity near threshold, PPF seen with ISIs between 10 and $200 \mathrm{msec}$ was decreased during L-fucose superfusion. This further confirms influences on presynaptic transmitter release. The small but steady increase in population spike amplitude and slope function of the fEPSP during incubation with L-fucose also can be interpreted in such a way (Figs. 1, 2, and 5B) (Matthies et al. 1996).

An enhanced $\mathrm{K}^{+}$-stimulated amino acid release in the presence of L-fucose has been directly demonstrated. This effect is concentration-dependent, from $10 \mu \mathrm{M}$ to $100 \mu \mathrm{M}$, and stereospecific. Because stereospecificity of L-fucose on LTP has been demonstrated by our earlier work (Matthies et al. 1996) and in our paired-pulse experiments, changes in osmolarity can be excluded. The effect of L-fucose on transmitter release was unaffected by AP5. L-Fucose also did not influence ligand binding to glutamate receptors, especially NMDA (H. Schroeder, unpublished data). Therefore, our data do not favor a direct action of L-fucose on glutamate receptors.

Besides the presynaptic effects of L-fucose, we investigated the influence on LTP induction at the postsynaptic site. Enhanced glutamate release during and for a restricted time after tetanic stimulation may be important for induction and early maintenance of LTP (Bliss et al. 1993; Canevari et al. 1994). At the postsynaptic side, activation of the glutamatergic NMDA receptor is the key event of LTP induction (Collingridge and Bliss 1987; Bliss and Collingridge 1993). In addition, activation of the metabotropic glutamate receptors modulates extent and duration of LTP (Musgrave et al. 1993; Bortolotto et al. 1994). LTP can be prevented by blockade of the NMDA receptor-ion channel complex with competitive antagonists such as AP5 (Collingridge and Bliss 1987) and noncompetitive antagonists binding to the ion channel pore, such as MK-801 (Coan et al. 1987). Late LTP can also be blocked by the competitive antagonist MCPG at metabotropic glutamate receptors (Little et al. 1995; Riedel et al. 1996; Wilsch et al. 1998). If L-fucose enhances glutamate release, the effect of competitive glutamate antagonists, but not that of noncompetitive inhibitors, would be partially antagonized. Competitive inhibitors of the NMDA receptor can be replaced in a pharmacokinetic manner by higher glutamate concentrations in the synaptic cleft by
L-fucose application in combination with high-frequency stimulation. Our results with coapplication of AP5, MK 801, and MCPG support this idea. Only the effect of competitive inhibitors was attenuated; the blocking effect of MK 801 on LTP was not influenced.

The increase in glutamate release by $\mathrm{L}$-fucose might also be a key event for the memory enhancement by Lfucose observed earlier (Wetzel et al. 1980). Ragozzino et al. (1996) discussed some mechanisms for glucose that also may be relevant for L-fucose, e.g., increase of transmitter synthesis, direct antagonism at opiate receptors that govern transmitter release, or direct influence on glutamate release. In addition, the role of 2-deoxy-D-glucose, which induces long-term potentiation in the CA1 region, in increasing glutamate release and presynaptic NMDA receptor-mediated $\mathrm{Ca}^{++}$influx has been discussed (Zhao \& Krnjevic 2000).

Because receptors and ion channels are glycoproteins (Hullebroeck and Hampson 1992; Kawamoto et al. 1995, Clark et al. 1998, Smalla et al. 1998), the application of L-fucose can interfere with interactions between these glycoproteins and endogenous lectins, which could serve as functional modulators. There are several reports on the existence of such endogenous lectins (i.e., Gagneux and Varki 1999), in particular, in the rat hippocampus (Gabius and Bardosi 1990), although their molecular identity is still not known. Meanwhile, experiments with several plant lectins demonstrated changes in glutamate receptor desensitization (Thio et al. 1993; Yue et al. 1995), and the DIDS-sensitive $\mathrm{Ca}^{++}$influx was shown to be twofold in the presence of the fucose-specific Ulex europaeus lectin I (Engelmann et al. 1991).

To summarize our results, L-fucose has been shown to increase presynaptic glutamate release and to interfere with competitive glutamate receptor antagonists in LTP expression. This can explain the LTP- and memory-enhancing effects of L-fucose.

\section{MATERIALS AND METHODS}

\section{LTP Experiments}

The experiments were performed in hippocampal slices from 8-week-old male Wistar rats, strain Shoe: wist (shoe). Slice preparation from rat hippocampus and extracellular recordings from the CA1 stratum radiatum were performed as described previously (Matthies et al. 1999). Animals were killed by a blow to the neck, and the hippocampus was quickly prepared. Transverse slices (400 $\mu$ m-thick) of the right hippocampus were prepared with a tissue chopper and were placed into a recording chamber containing artificial cerebral spinal fluid (ACSF) immediately after preparation. The ACSF was a modified Krebs-Ringer solution containing (in $\mathrm{mM}$ ): $\mathrm{NaCl}, 124 ; \mathrm{KCl}, 4.9 ; \mathrm{KH}_{2} \mathrm{PO}_{4}, 1.2 ; \mathrm{MgSO}_{4}, 1.3 ; \mathrm{CaCl}_{2}, 2.5 ; \mathrm{NaHCO}_{3}$, 25.6; D-glucose, 10; ( $\mathrm{pH} 7.4$ ). ACSF was saturated with $95 \% \mathrm{O}_{2} / 5 \%$ $\mathrm{CO}_{2}$. Slices were kept submerged and were perfused with a flow rate of $1 \mathrm{ml} / \mathrm{min}$ (temperature $35^{\circ} \mathrm{C}$ ). Field potentials in the CA1 region were evoked by stimulating the Schaffer collateral-commissural pathway with biphasic square wave constant current im-

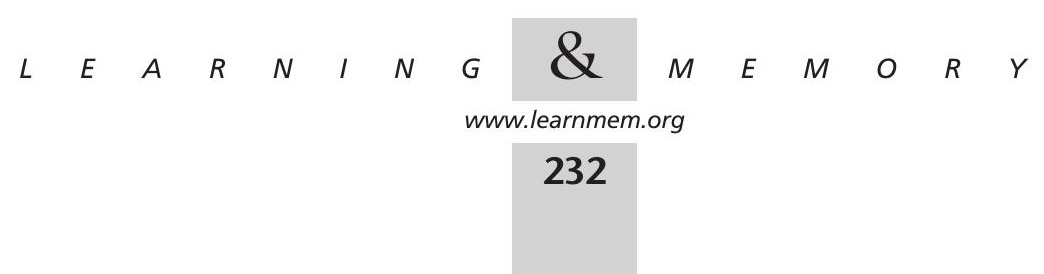


pulses of $0.1 \mathrm{msec}$ duration per half wave generated by an A-MSystems Stimulator (Model 2001). A lacquer-coated monopolar stainless-steel electrode was used to stimulate the test input. To record the extracellular field potentials, a glass electrode filled with ACSF was inserted into the stratum radiatum of the CA1. The stimulus intensity was adjusted to elicit a field potential of $30-40 \%$ of maximum response. Four single test potentials were amplified by a DC amplifier and averaged for each test record. The fEPSP was evaluated by measuring the initial, increasing slope $(\mathrm{mV} / \mathrm{msec})$ between the onset of the response and its negative peak in recordings from the field potentials in the CA1-region. Stable recordings were obtained over a $30 \mathrm{~min}$ baseline period.

LTP in the CA1 region was induced by tetanizing the Schaffer collateral input with three $100-\mathrm{Hz}$ stimulus trains, each containing 50 pulses at double pulse width and with a 5 min interval between each train. Thereafter, the fEPSP slope was recorded in 5-10 min intervals after tetanization.

To test the interactions of L-fucose with glutamate antagonists at the NMDA and metabotropic glutamate receptors, the slices were incubated with $0.2 \mathrm{~mm} \mathrm{~L}$ - or D-fucose for $60 \mathrm{~min}$ before, during, and $20 \mathrm{~min}$ after the tetanization procedure. AP5 (50 $\mu \mathrm{M})$, MK-801 $(15 \mu \mathrm{M})$, or MCPG $(500 \mu \mathrm{M})$ were additionally applied to the perfusion bath before and during LTP-induction and were washed out immediately after tetanization.

\section{Paired-Pulse Facilitation}

Paired-pulse facilitation (PPF) was produced by applying two stimulation pulses with identical intensity separated by $50 \mathrm{msec}$ to the same stimulation electrode. Facilitation was expressed numerically as the ratio of the second response to the first (R2/R1). The influence of fucose was tested in two experimental paradigms: In each case, after taking a baseline from untreated slices, either $0.2 \mathrm{~mm}$ L-fucose or $0.2 \mathrm{~mm} \mathrm{D-fucose}$ was superfused for $60 \mathrm{~min}$ and then washed out. Field potentials were recorded before, during, and after perfusion with fucose-containing medium.

In a first series of experiments, input/output curves were constructed using four stimulus intensities. Threshold intensity for the fEPSP (which evoked an measurable potential) was multiplied by a factor $1.5,2$, and 2.5 . The intensity dependence of PPF could be measured with this paradigm.

In a second series of experiments, with near-threshold intensity that evoked a measurable response, the ISI was varied from 10 $\mathrm{msec}$ to $500 \mathrm{msec}$. To summarize data from several experiments, the slope function of both the first and second fEPSP were normalized to the slope function of the first fEPSP during the control period and were then averaged before calculating the single fEPSP and the PPF ratio.

\section{Amino Acid Release}

For the amino acid release study, freshly prepared hippocampal slices were incubated in Krebs-Henseleit solution with $19.2 \mathrm{~nm}$ [ $\left.{ }^{3} \mathrm{H}\right]$-D-aspartate (specific activity $962 \mathrm{GBq} / \mathrm{mmole}$, NEN-Dupont, USA) for $10 \mathrm{~min}$ under aeration with carbogen $\left(\mathrm{O}_{2} / \mathrm{CO}_{2}\right.$ ratio $=95 \% / 5 \%$ ), transferred into superfusion chambers, and rinsed with a calcium-free medium. Thereafter, the superfusion was started with $\mathrm{Mg}^{++}$-free oxygenated Krebs-Henseleit solution at a flow rate of $0.5 \mathrm{ml} / \mathrm{min}$. After 21 to $25 \mathrm{~min}\left(\mathrm{~S}_{1}\right)$, the medium was changed to a Krebs-Henseleit solution containing $48 \mathrm{~mm} \mathrm{KCl}$ or 48 $\mathrm{mm} \mathrm{KCl}$ with different concentrations of L-fucose and $\mathrm{D}-$ fucose. The perfusate was collected in 1-min fractions up to $30 \mathrm{~min}$ and assayed for radioactivity using a scintillation cocktail containing dioxane. Data were calculated as dpm per mg protein.

\section{Statistics}

Data were calculated as means \pm standard error of the means (s.E.M.). Statistical comparisons were made using the two-tailed Utest of Mann and Whitney. Significance was considered at the $P<0.05$ level.

\section{Substances}

L-Fucose, D-fucose, and D,L-2-amino-5-phosphonovalerate (AP5) were purchased from Sigma and dissolved in ACSF. (5R,10S)-(+)-5Methyl-10,11-dihydro-5H-dibenzo[a,d]cyclohepten-5,10-imine hydrogen maleate (MK-801) and (S)- $\alpha$-methyl-4-carboxyphenylglycine (MCPG) from Tocris were dissolved in ACSF.

\section{ACKNOWLEDGMENTS}

This work was supported by the Deutsche Forschungsgemeinschaft (DFG grant Kr 1255/4-2). We thank Karin Schulzeck, Inge Schwarz, and Grit Blaschke for excellent technical assistance and Mr. Toms for help in improving the English style.

The publication costs of this article were defrayed in part by payment of page charges. This article must therefore be hereby marked "advertisement" in accordance with 18 USC section 1734 solely to indicate this fact.

\section{REFERENCES}

Alexinsky, T., Przybyslawski, J., Mileusnic, R., Rose, S.P.R., and Sara, S.J. 1997. Antibody to day-old chick brain glycoprotein produces amnesia in adult rats. Neurobiol. Learn. Mem. 67: 14-20.

Angenstein, F., Matthies, H., Jr., Staeck, S., Reymann, K.G., and Staak, S 1992. The maintenance of hippocampal long-term potentiation is paralleled by a dopamin-dependent increase in glycoprotein fucosylation. Neurochem. Int. 21: 403-408.

Bliss, T.V.P., Douglas, R.M., Errington, M.L., and Lynch, M.A. 1986. Correlation between long-term potentiation and release of endogenous amino acids from dentate gyrus of anaesthetized rats. J. Physiol. 377: 391-408.

Bliss, T.V.P. and Collingridge, G.L. 1993. A synaptic model of memory: long-term potentiation in the hippocampus. Nature 361: 31-39.

Bortolotto, Z.A., Bashir, Z.I., Davies, C.H., and Collingridge, G.L. 1994. A molecular switch activated by metabotropic glutamate receptors regulates induction of long-term potentiation. Nature 368: 740-743.

Breen, K.C., Coughlan, C.M., and Hayes, F.D. 1998. The role of glycoproteins in neuronal development, function, and disease. $\mathrm{Mol}$. Neurobiol. 16: 163-220.

Canevari, L., Richter-Levin, G., and Bliss, T.V.P. 1994. LTP in the dentate gyrus is associated with a persistent NMDA receptor-dependent enhancement of synaptosomal glutamate release. Brain Res. 667: 115-117.

Clark, R.A.C., Gurd, J.W., Bissoon, N., Tricaud, N., Molnar, E., Zamze, S.E., Dwek, R.A., McIlhinney, R.A.J., and Wing, D.R. 1998. Identification of lectin-purified neural glycoproteins, GPs 180, 116, and 110 with NMDA and AMPA receptor subunits: Conservation of glycosylation at the synapse. J. Neurochem. 70: 2594-2605.

Coan, E.J., Saywood, W., and Collingridge, G.L. 1987. MK-801 blocks NMDA receptor-mediated synaptic transmission and long term potentiation in rat hippocampal slices. Neurosci. Lett. 80: 111-114.

Collingridge, G.L. and Bliss, T.V.P. 1987. NMDA-receptors-their role in long-term potentiation. TINS 10: 288-293.

Commins, S., Gigg, J., Anderson, M., and O'Mara, S.M.. 1998. Interaction between paired-pulse facilitation and long-term potentiation in the projection from hippocampal area CA1 to the subiculum. Neuroreport 9: 4109-4113.

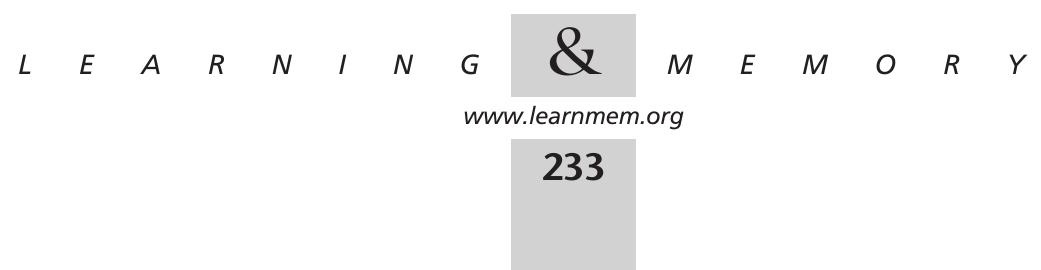


Crowe S.F., Zhao, W.Q., Sedman, G.L., and Ng, K.T. 1994 2-deoxygalactose interferes with an intermediate processing stage of memory. Behav. Neural Biol. 61: 206-13.

Durkin, T.P., Messier, C., de Boer, P., and Westerink, B.H.C. 1992. Raised glucose levels enhance scopolamine-induced acetylcholine outflow from the hippocampus: an in vivo microdialysis study in the rat. Behav. Brain Res. 49: 181-188.

Engelmann, B., Schumacher, U., and Duhm, J. 1991. Role of ABH blood group antigens in the stimulation of a DIDS-sensitive $\mathrm{Ca}^{2+}$ influx pathway in human erythrocytes by Ulex europaeus agglutinin I and a monoclonal anti A1 antibody. Biochim. Biophys. Acta 1091: 261-269.

Frey, U. and Morris, G.M.. 1997. Synaptic tagging and long-term potentiation. Nature 385: 533-536.

Gabius, H.-J. and Bardosi, A. 1990. Regional differences in the distribution of endogenous receptors for carbohydrate constituents of cellular glycoconjugates, especially lectins, in cortex, hippocampus, basal ganglia and thalamus of adult human brain. Histochemistry 93: 581-592.

Gagneux, P. and Varki, A. 1999. Evolutionary considerations in relating oligosaccharide diversity to biological function. Glycobiology 9: 747-755.

Hullebroeck, M.F. and Hampson, D.R. 1992. Characterization of the oligosaccharide side chains on kainate binding proteins and AMPA receptors. Brain Res. 590: 187-192.

Izumi, Y., Clifford, D.B., and Zorumski, C.F. 1991.

2-Amino-3-phosphonopropionate blocks the induction and maintenance of long-term potentiation in rat hippocampal slices. Neurosci. Lett. 122: 187-190.

Jork, R., Grecksch, G., and Matthies, H. 1986. Impairment of glycoprotein fucosylation in rat hippocampus and the consequences on memory formation. Pharmacol. Biochem. Behav. 25: 1137-1144.

Jork, R., Schnurra, J., Smalla, K.-H., Grecksch, G., Popov, N., and Matthies, H. 1989. Deoxy-galactose mediated amnesia is releated to inhibition of training-induced increase in rat hippocampal glycoprotein fucosylation. Neurosci. Res. Comm. 5: 3-8.

Kato, K., Li, S.-T., and Zorumski, C.F. 1999. Modulation of long-term potentiation induction in the hippocampus by $\mathrm{N}$-methyl-D-aspartate-mediated presynaptic inhibition. Neurosci. 92: 1261-1272.

Kawamoto, S., Hattori, S., Sakimura, K., Mishina, M., and Okuda, K. 1995. $N$-linked glycosylation of the alpha-amino-3-hydroxy-5-methylisoxazole-4-propionate (AMPA)-selective glutamate receptor channel alpha 2 subunit is essential for the acquisition of ligand-binding activity. J. Neurochem. 64: 1258-1266.

Krug, M., Koch, M., Schoof, E., Wagner, M., and Matthies, H. 1989. Methylglucamine orotate, a memory-improving drug, prolongs hippocampal long-term potentiation. Eur. J. Pharmacol. 173: 223-226.

Krug, M., Jork, R., Reymann, K.G., Wagner, M., and Matthies, H. 1991. The amnesic substance 2-deoxy-D-galactose suppresses the maintenance of hippocampal LTP. Brain Res. 540: 237-242.

Krug, M., Wagner, M., Staak, S., and Smalla, K.-H. 1994. Fucose and fucose-containing sugar epitopes enhanced hippocampal long-term potentiation in the freely moving rats. Brain Res. 643: 130-135.

Leung, L.S. and Fu, X.-W. 1994. Factors affecting paired-pulse facilitation in hippocampal CA1 neurons in vitro. Brain Res. 650: 75-84.

Little, Z., Grover, L.M., and Teyler, T.J. 1995. Metabotropic glutamate receptor antagonist, (R,S)-alpha-methyl-4-carboxyphenyglycine, blocks two distinct forms of long-term potentiation in area CA1 of rat hippocampus. Neurosci. Lett. 201: 73-76.

Matthies, H. 1988. In search of cellular mechanisms of memory. Neurobiology 32: 277-349.
Matthies, H., Jr., Staak, S., and Krug, M. 1996. Fucose and fucosyllactose enhance in-vitro hippocampal long-term potentiation. Brain Res. 725: 276-280.

Matthies, H., Jr., Kretlow, J., Matthies, H., Smalla, K.-H., Staak, S., and Krug, M. 1999. Glycosylation of proteins during a critical time window is necessary for the maintenance of long-term potentiation in the hippocampal CA1 region. Neuroscience 91: 175-183.

Mennerick, S. and Zorumski, C.F. 1996. Postsynaptic modulation of NMDA synaptic currents in rat hippocampal microcultures by paired-pulse stimulation. J. Physiol. 490.2: 405-417.

Musgrave, M.A., Ballyk, B.A., and Goh, J.W. 1993. Coactivation of metabotropic and NMDA receptors is required for LTP induction. Neuroreport 4: 171-174

Ragozzino, M.E., Unick, K.E., and Gold, P.E. 1996. Hippocampal acetylcholine release during memory testing in rats: augmention by glucose. Proc. Natl. Acad. Sci. 93: 4693-4698.

Regan, C.M. and Fox, G.B. 1995. Polysialylation as a regulator of neural plasticity in rodent learning and aging. Neurochem. Res. 20: 593-598.

Riedel, G., Wetzel, W., and Reymann, K.G. 1996. Comparing the role of metabotropic glutamate receptors in long-term potentiation and in learning and memory. Neuropsychopharmacol. \& Biol. Psychiat. 20: 761-789.

Rose, S.P.R. 1995. Cell-adhesion molecules, glucocorticoids and long-term-memory formation. TINS 18: 502-506.

Schulz, P.E., Cook, E.P., and Johnston, D. 1994. Changes in paired-pulse facilitation suggest presynaptic involvement in long-term potentiation. J. Neurosci. 14: 5325-5337.

Smalla, K.-H., Angenstein, F., Richter, K., Gundelfinger, E.D., and Staak, S. 1998. Identification of fucose a(1-2) galactose epitope-containing glycoproteins from rat hippocampus. Neuroreport 9: 813-817.

Thio, L.L., Clifford, D.B., and Zorumski, C.F. 1993. Blockade of ionotropic quisqualate receptor desensitisation in rat hippocampal neurons by wheatgerm agglutinin and other lectins. Neuroscience 52: 35-44.

Varki, A. 1993. Biological roles of oligosaccharides: All of the theories are correct. Glycobiology 3: 97-130.

Watkins, J. and Collingridge, G. 1994. Phenylglycine derivatives as antagonists of metabotropic glutamate receptors. Trends Pharmacol. Sci. 15: 333-342.

Wetzel, W., Popov, N., Loessner, B., Schulzeck, S., Honza, R., and Matthies, H. 1980. Effect of L-fucose on brain protein metabolism and retention of a learned behavior in rats. Pharmacol. Biochem. Behav. 13: $765-771$.

Wilsch, V.W., Behnisch, T., Jäger, T., Reymann, K.G., and Balschun, D. 1998. When are class I metabotropic glutamate receptors necessary for long-term potentiation? J. Neurosci. 18: 6071-6080.

Yue, K.-T., MacDonald, J.F., Pekhletski, R., and Hampson, D.R. 1995. Differential effects of lectins on recombinant glutamate receptors. Europ. J. Pharmacol. 291: 229-235.

Zablocka, B. and Domanska-Janik, K. 1994. PAF antagonist BN52021 inhibits ${ }^{3} \mathrm{H}$-D-aspartate release after ischemia in vitro. Neuroreport 6: 85-88.

Zhao, Y.-T. and Krnjevic, K. 2000. 2-deoxyglucose-induced long-term potentiation in CA1 is not prevented by intraneuronal chelator. $J$. Neurophysiol. 83: 177-180.

Zucker, R.S. 1989. Short-term synaptic plasticity. Annu. Rev. Neurosci. 12: $13-31$.

Received December 28, 1999; accepted in revised form May 19, 2000.

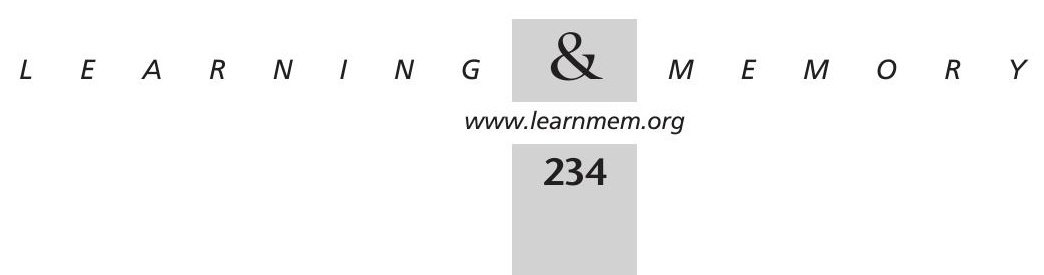




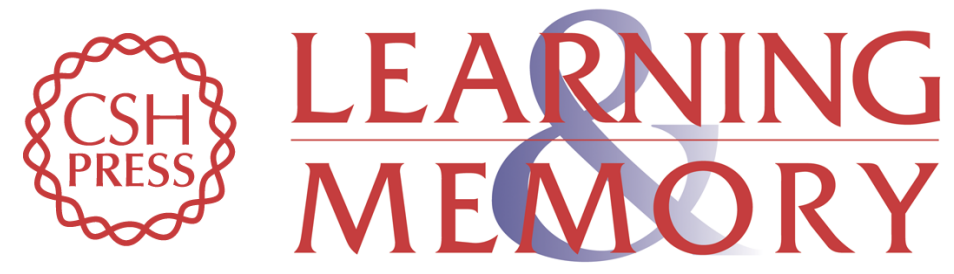

Enhancement of Glutamate Release by I-Fucose Changes Effects of Glutamate Receptor Antagonists on Long-Term Potentiation in the Rat Hippocampus

Henry Matthies, Helmut Schroeder, Karl-Heinz Smalla, et al.

Learn. Mem. 2000, 7:

Access the most recent version at doi:10.1101//m.7.4.227

References This article cites 46 articles, 3 of which can be accessed free at: http://learnmem.cshlp.org/content/7/4/227.full.html\#ref-list-1

License

Email Alerting

Receive free email alerts when new articles cite this article - sign up in the box at the Service top right corner of the article or click here. 